\title{
Wechsel in der Schriftleitung
}

\author{
Change in the Editorial Board
}

Herr San.-Rat Prof. Dr. Drs. h. c. F. C. Sitzmann hat zum Ende des Jahres 2007 nach 37-jähriger Tätigkeit die Schriftleitung der Klinischen Pädiatrie übergeben.

Nach dem Beginn der Mitarbeit in der Herausgeberschaft im Jahre 1970 mit W. Burmeister, Bonn, hat F.C. Sitzmann ab 1982 gemeinsam mit G. Heimann, Aachen, sowie ab 2006 mit U. Göbel die Klinische Pädiatrie als verantwortlicher Schriftleiter editiert. Die Zeitschrift hat in dieser langen Spanne stetig an Kontur und Attraktivität für Leser und Autoren gewonnen und reflektiert die thematische Entwicklung in der akademischen Kinder- und Jugendmedizin. Unter F. C. Sitzmanns Leitung wurde der wissenschaftliche Nachwuchs, neben etablierten Autoren, ermutigt, insbesondere auch Neuentwicklungen in der Kinder- und Jugendmedizin aufzugreifen. Die differenzierte Abbildung von Schwerpunkten, wie die der pädiatrischen Onkologie und Hämatologie, vermehrte Publikationshäufigkeit klinischer Studien sowie die Akzentuierung von Kasuistiken hin zur „Visite“ mögen die jüngsten Schritte der Entwicklung belegen, die F.C. Sitzmann einleitete und mit voller Kraft vorantrieb. Er erreichte als Herausgeber somit, die relevanten und aktuellen Aspekte der Entwicklung unseres Fachs in seiner gesamten Breite, aber auch Tiefe zu berücksichtigen. Dies wird auch durch die steten erfreulichen Anstiege des Impact Factors der Klinischen Pädiatrie reflektiert.

Die Mitherausgeber und der Verlag sowie die gesamte Autorenschaft und die Leser der Klinischen Pädiatrie als Repräsentanten unseres Faches haben F.C. Sitzmann viel mehr zu verdanken, als diese Zeilen es auszudrücken vermögen.

Dieses Editorial soll und kann keine Laudatio sein, eine skizzenhafte Darstellung seiner Vita sei jedoch erlaubt.

F.C. Sitzmann wurde 1935 in Thurn/Oberfranken geboren und begann nach dem Abitur 1953 sein Medizinstudium an der Friedrich-AlexanderUniversität Erlangen, nach medizinischem Staatsexamen und Promotion im Jahre 1959 Eintritt in die Pflichtassistentenzeit, im Jahre 1961 Beginn der Facharztweiterbildung für Kinderheilkunde an der Universitäts-Kinderklinik Erlangen unter der Leitung von Prof. Dr. A. Windorfer, welche ergänzt durch einen Auslandsaufenthalt 1963 an der Universitäts-Kinderklinik Graz - im Jahre 1965 ihren Abschluss fand und in die Ernennung zum Oberarzt der Poliklinik der Universitäts-Kinderklinik Erlangen mündete. Dort im Jahre 1967 Habilitation für Kinderheilkunde mit dem Thema „Mikromethoden zur Messung von Enzymaktivitäten im Serum“. 1970 erfolgte die Ernennung zum leitenden Oberarzt der Universitäts-Kinderklinik Erlangen, im Jahre 1977 der Ruf auf den Lehrstuhl für Kinderheilkunde und Ernennung zum Direktor der Klinik für Kinder- und Jugendmedizin an der Universität des Saarlandes in Homburg/Saar. In den 27 Jahren bis zu seiner Emeritierung im Jahre 2004 hat F.C. Sitzmann neben der Herausgeberschaft der Klinischen Pädiatrie eine Reihe weiterer Aufgaben wahrgenommen, u. a. die Mitgliedschaft in der ständigen Impfkommission am Robert-Koch-Institut, Berlin (STIKO) von 1983 bis 2003, daneben war F.C. Sitzmann Ärztlicher Direktor des Universitätsklinikums Homburg/Saar von 1985 bis 1986 sowie Dekan der Medizinischen Fakultät der Universität des Saarlandes in den Jahren 1995-1996. F.C. Sitzmann wurde mit der Ernst-von-BergmannPlakette der deutschen Ärzteschaft im Jahre 1985 und 2001 mit der Carl-Alken-Medaille der Ärztekammer des Saarlandes ausgezeichnet. In den Jahren 2002 und 2004 wurde ihm die Ehrendoktorwürde der Universität Damaskus/Syrien und der Universität Conakry/Guinea verliehen.

Diese Darstellung der Vita mag belegen, welche enormen Verdienste um die Kinder- und Jugendmedizin F.C. Sitzmann sich insgesamt erworben hat.

Die Herausgeber der Klinischen Pädiatrie und der Georg Thieme Verlag danken F.C. Sitzmann abschließend herzlich für seine unablässige Aktivität zur Fortentwicklung der Klinischen Pädiatrie und für die überragende menschliche und fachliche Kompetenz, nicht nur bei den großen Weichenstellungen, sondern auch bei der tagtäglichen Redaktionsarbeit. Die Entwicklung der Klinischen Pädiatrie zu einer nunmehr auch international hoch angesehen pädiatrischen Zeitschrift ist der beste Indikator für die Qualität der Arbeit. Diese ist uns Verpflichtung, als Herausgeber der Klinischen Pädiatrie den eingeschlagenen Weg mit allem Nachdruck fortzusetzen, um den wissenschaftlichen Stellenwert der Zeitschrift weiter auszubauen.

Georg Thieme Verlag

Volker Niem, Programmplaner

Die Herausgeber

Prof. Dr. Ulrich Göbel, Düsseldorf

Prof. Dr. Ludwig Gortner, Homburg/Saar 